\title{
La gastronomía peregrina de Gabriel García Márquez*
}

\author{
Fernando Valerio-Holguín ${ }^{1}$ \\ Colorado State University (EE. UU.)
}

\section{Resumen}

A lo largo de los Doce cuentos peregrinos, de Gabriel García Márquez, se mencionan platillos de la cocina latinoamericana e internacional, así como referencias a situaciones, personas y restaurantes relacionados con la gastronomía. Este artículo examina la peregrinación gastronómica o paratopía de los personajes de estos cuentos. El desplazamiento tanto de los cuerpos como de la comida en el espacio y el tiempo plantea una posición incómoda de la enunciación por parte del escritor, así como de los enunciados de los personajes. Por una parte, la función de la comida tiene como objetivo definir el carácter, el estatus social y la identidad cultural de los personajes $y$, por otra, establecer una poética relacional en el espacio social en que se desenvuelven dichos personajes.

\section{Abstract}

Throughout the stories of Strange Pilgrims by Gabriel García Márquez there are references to dishes of Latin American and international cuisine, as well as to situations, peopleand restaurants related to gastronomy. This article examines the gastronomic pilgrimage or paratopia of the characters in these stories. The displacement of both bodies and food in space and time poses an uncomfortable position of enunciation for the writer, as well as the statements of the characters. On the one hand, the function of food aims to define the personality, social status and cultural identity of the characters and, on the other hand, establish a relational poetic in the social space in which these characters perform.

\footnotetext{
* Gabriel García Márquez: Pilgrimage and Gastronomy Recibido: 25 de octubre de 2017 - Aprobado: 30 de noviembre de 2017

1 Doctor en Literatura por la Universidad de Tulane (EE. UU.). Profesor del Department of Foreign Languages and Literatures de Colorado State University. e-mail: fvalerio@mail.colostate.edu.
} 
Palabras clave: gastronomía, Keywords: gastronomy, body, cuerpo, exilio, paratopía, pere- exile, paratopia, pilgrimage, grinación, identidad cultural. cultural identity.

\section{Introducción: gastronomía y placer del texto}

En Doce cuentos peregrinos (1992), de Gabriel García Márquez abundan las referencias a platillos de la cocina latinoamericana e internacional, así como a restaurantes, situaciones y personajes relacionados con la gastronomía. En el "Prólogo", García Márquez establece un paralelo entre la cocina y el proceso de escritura: "Es un secreto del oficio que no obedece a las leyes de la inteligencia sino a la magia de los instintos, como sabe la cocinera cuando está la sopa" (19. La cursiva es mía). Y no es sólo un saber del oficio lo que está en juego, sino también el placer que se deriva de ambas actividades: "Lo demás es el placer de escribir, el más íntimo y solitario que pueda imaginarse [...] (15. La cursiva es mía). También expresa: "La escritura se me hizo entonces tan fluida que a ratos me sentía escribiendo por el puro placer de narrar [...]" (18). El placer de narrar, de cocinar y vivir conduce al sujeto a una adicción. Al respecto, expresa el escritor colombiano: "[...] qué insaciable y abrasivo es el vicio de escribir" (13).

Si la hipergrafía y la gula son vicios, vivir también se convierte en una adicción. ${ }^{2}$ El escritor deviene, entonces, como el personaje Cesare Zavattini, en un "[G]oloso de la vida" (72). Y si no goloso o buen cocinero, el escritor es, entonces, un gourmand: "Miguel Otero Silva, que además de buen escritor era un anfitrión espléndido y un comedor refinado, nos esperaba con un almuerzo de nunca olvidar" (130). El sabor y el saber, que confluyen en la escritura de Doce cuentos peregrinos de García Márquez, se producen en los espacios paradójicos o paratópicos de la migración. La comida tiene como objetivo, por una parte, definir el carácter, el estatus social y la identidad cultural de los personajes y, por otra, establecer una poética relacional en el espacio social en que se desenvuelven dichos personajes. Mi propósito en este ensayo consiste en analizar las referencias culinarias, intrínsecamente ligadas a la paratopía de unos sujetos en la construcción de una identidad cultural, a través de sus cuerpos con relación a espacios sociales paradójicos.

\footnotetext{
${ }^{2}$ Se puede definir "hipergrafía" como la compulsión que lleva a un escritor a escribir permanentemente. La necesidad de escribir se puede comparar con la ingestión constante de comida. Gula y escritura quedan entonces vinculadas.
} 


\section{Peregrinación: desplazamientos paratópicos, no-lugares y extrañeza}

En esta colección de cuentos son peregrinos los personajes y peregrinos también los platos de la gastronomía. En la etimología de la palabra peregrino se encuentra el sentido de visitar el extranjero o también los lugares sagrados, lo que sugiere que los personajes latinoamericanos de esos textos visitan los lugares "sacralizados" de la cultura europea: París, Roma, Ginebra, Barcelona y Madrid. ${ }^{3} \mathrm{Si}$ peregrinos son los cuentos y el escritor, que en algunas ocasiones se involucra a través de la primera persona del plural o la primera persona del singular, creando un pacto autobiográfico parcial ${ }^{4}$, así también son peregrinos la escritura y el género literario. En algún momento, García Márquez pensó que escribiría una novela con esos temas, pero no fue sino hasta 1974 en que se dio cuenta de que adoptaría el género del cuento. De manera tal que, durante dieciocho años, tenemos la peregrinación de esos textos por diferentes países, géneros literarios y medios artísticos. Las lenguas habladas por los personajes que trashuman por las ciudades europeas también apuntan a un desplazamiento. Los narradores enfatizan los acentos, las entonaciones y las dificultades de los hablantes extranjeros. Los personajes latinoamericanos sufren un extrañamiento en las lenguas europeas, por lo que tienen que negociar su identidad en las rupturas del sentido. ${ }^{5}$

\footnotetext{
${ }^{3}$ La palabra "peregrino", del latín peregrinus, significa "viajero" o "el que va al extranjero". Durante sus dieciocho años de peregrinación por Europa y Latinoamérica, García Márquez llegó a acumular sesenta y cuatro temas anotados para escribir cuentos, que se le perdieron en México alrededor de 1978 ("Prólogo", 16). De estos, sólo treinta fueron reescritos y dieciocho sobrevivieron al escrutinio del escritor, hasta terminar depurándolos en los doce cuentos que conocemos en su forma actual. Así mismo, este material sufrió sus avatares con respecto al género literario. Algunos de estos textos vieron la luz en forma de crónicas periodísticas, guiones de películas y series de televisión.

${ }^{4}$ Philippe Lejeune (1996) denomina "pacto autobiográfico" a la identidad entre el escritor, el narrador y el personaje. En el caso de los cuentos de Doce cuentos peregrinos, el narrador, que se incluye en primera persona del singular y del plural, menciona datos biográficos que pueden identificar a Gabriel García Márquez en su recorrido por Europa.

${ }^{5}$ Otras referencias a lenguas extranjeras incluyen las siguientes: en "Me alquilo para soñar", los estudiantes inventaron para Frau Frida un "trabalenguas germánico" (95). María dos Prazeres, inmigrante brasileña de Manaos, radicada en Barcelona, dicta su testamento en "catalán medieval" (145). En el mismo cuento, el hombre joven que le ofrece llevarla en el auto habla en un "catalán difícil", por lo que tiene que continuar la conversación en "castellano" (153). En el cuento "El rastro de tu sangre en la nieve", el guardián del hospital "se cagó en su madre (la madre de Billy) en francés" (238). En "El verano feliz de la señora Forbes", un grupo de mujeres "rezaban en dialecto" (205) delante del cadáver expuesto de la Señora Forbes.
} 
La dimensión paratópica de los personajes genera un extrañamiento que contamina la significación de los textos. La paratopía peregrinación, desplazamiento, exilio- es un concepto que abarca prácticamente no sólo los cuentos y su proceso de escritura, sino también todas las actividades alrededor de la comida, su ingesta y los personajes que la consumen. Con respecto a la paratopía, Kristine Vanden Berghe (2001) explica:

\begin{abstract}
Una implicación fundamental de la posición paradójica o paratopía, es que el escritor constantemente explota las roturas que se abren en la sociedad. Se presenta entonces como bohemio, solitario, artista, o simplemente, distinto de alguna forma de los demás: Maingueneau lo define como el que no está en su lugar allí donde está, el que se desplaza de un lugar a otro sin arraigarse nunca de manera más o menos definitiva, el que no encuentra su lugar, el que no se acomoda. (87. Las cursivas son mías)
\end{abstract}

Como ejemplos de la paratopía de estos personajes, en "Buen viaje, señor presidente", un ex presidente se encuentra exiliado en Martinica y de visita médica en Ginebra, viviendo en la pobreza después de haber sido depuesto en su país de origen. Así mismo, en "La santa", Margarito Duarte lleva el cadáver de su niña a Roma para que sea canonizada por el Papa en el Vaticano. En "Me alquilo para soñar", el narrador, Frau Frida y Neruda coinciden accidentalmente en diferentes ciudades europeas. Por último, en "María dos Prazeres", una prostituta retirada que reside en Barcelona se prepara para la muerte. Si estos personajes se encuentran en una posición paratópica en las ciudades europeas, algunos espacios en las mismas constituyen lo que Marc Augé denomina "no-lugares". En su libro Non-Places, Augé (1995) denomina no-lugares a aquellos espacios con los que un sujeto no puede relacionarse ni afectiva ni cognitivamente. Algunos espacios incluyen aeropuertos, autopistas, supermercados y hoteles. Aunque Augé está mucho más interesado en los espacios que en los sujetos que habitan esos espacios, también se podría denominar no-individuos (o deshumanizados) a aquéllos con los cuales es difícil relacionarse afectiva y cognitivamente. La imposibilidad de reconocer un lugar (o a un individuo) como propio o de identificarse afectivamente con el mismo es producto de una "extrañeza perturbadora". De acuerdo con Freud (citado por Clancier, 1979), la "extrañeza inquietante o perturbadora", como sería preferible traducir el término alemán unheimlich, consiste en el malestar de una experiencia que linda con la angustia y que se presenta a partir de la repetición de un hecho banal: "La extrañeza inquietante será ese 
tipo de espanto que se apega a las cosas conocidas desde hace mucho tiempo, y desde siempre familiares" (48). ${ }^{6}$

En Doce cuentos peregrinos, los personajes no sólo tienen que "negociar" la incomodidad de vivir en el exilio, sino que también se encuentran "deshumanizados" en hoteles, manicomios, hospitales, castillos, pensiones, cafeterías y restaurantes pobres. En "Sólo vine a hablar por teléfono", María de la Luz se ve confinada por equivocación en un hospital siquiátrico, separada y luego abandonada en el mismo por su novio. En "Buen viaje, señor presidente", el ex presidente se hospeda en un "hotel de cuarta categoría", almuerza en una "fonda de pobres" y luego es internado en un hospital para una intervención quirúrgica. Solo, sin familiares ni amigos, y en una ciudad extranjera (extraña), el ex presidente deberá enfrentar su destino. En "Diecisiete ingleses envenenados", Prudencia Linero se hospeda en la habitación de un complicado conjunto de hoteles baratos. El extrañamiento se evidencia en la descripción del elevador: "una jaula de gallina que subía muy despacio por el centro de una escalera [...] En el tercer piso el ascensor se detuvo [...] y entonces el maletero [...] abrió la puerta de rombos plegadizos [...]" (166).

En estos espacios de las ciudades europeas los personajes extranjeros perciben la realidad con un sentido de "desfamiliarización". ${ }^{7}$ El mismo García Márquez, en el "Prólogo," da cuenta de la sensación de extrañeza en el proceso creativo de estos textos y de los personajes mismos: "Ha sido una rara experiencia creativa que merece ser explicada [...]" (13. La cursiva es mía). 0 también: “[...] y pensé que era un buen punto de partida para escribir sobre las cosas extrañas que les suceden a los latinoamericanos en Europa" (14. La cursiva es mía). Es decir, que la incomodidad de la vida en el extranjero (extraño) ${ }^{8}$ se convierte en perturbadora (uncanny), fuera de casa (unheinlich).

\footnotetext{
${ }^{6}$ Es importante resaltar la ambivalencia del significado de la palabra alemana "heimlich", que, entre sus varios sentidos, posee "uno que coincide con su contrario unheimlich" (Freud citado por Clancier, 48). La percepción de lo absurdo no es más que otra forma de nombrar esta "extrañeza inquietante". El término "unheimlich" remite al neologismo en inglés "unhomely [uncanny]", que designa aquello que pertenece a la casa, pero que, aun siendo un objeto familiar, causa extrañeza.

7 Para los formalistas rusos, la desfamiliarización consiste en el fenómeno de presentar objetos y situaciones familiares como extraños en el arte. De esta manera, el sentido de esta palabra coincide con la de "extrañeza perturbadora".

${ }^{8}$ La palabra "extranjero" proviene del francés antiguo "strangier", que a su vez proviene de "strange [extraño]". De ahí que no sorprenda el "extrañamiento" al cual se enfrentan los personajes extranjeros en Europa.
} 
En este tipo de espacios tiene lugar la preparación de alimentos y su ingesta. De esta manera, nos encontramos frente a lo que denominaré una "peregrinación gastronómica" o "paratopía de los comensales". La paratopía, como desplazamiento temporal y espacial, tiene una importancia en cuanto a la comida, que puede o no ser originaria del país en el que se encuentran exiliados los personajes, sino vinculada, de alguna manera, a la cultura de origen. Todo lo anterior plantea también una paratopía del cuerpo que ingesta la comida. En "Me alquilo para soñar", Neruda, poeta chileno, se encuentra en Barcelona. ${ }^{9}$ En "El verano feliz de la señora Forbes", la institutriz alemana y los niños colombianos se encuentran en la isla Pantelleria, perteneciente a Italia. En "María dos Prazeres", una prostituta brasileña se encuentra retirada en Barcelona. La comida, entonces, sirve de mediación entre los personajes y, de alguna manera, en los cuerpos, que se "expresan" a través de la comida y se construyen como sujetos transnacionales a través de la comida. El mismo Gabriel García Márquez escribió estos cuentos durante dieciocho años de larga peregrinación por diferentes países. Como exiliados, los personajes de sus cuentos reflejan las posiciones incómodas en las que se encontró el escritor, desplazado de su país natal.

\section{Nostalgia, identidad cultural y "liminalidad" del cuerpo}

¿Cuál es la función de la gastronomía en estos espacios incómodos del exilio? ¿Mediar el extrañamiento, ligar al terruño natal, recuperar la identidad amenazada? En Doce cuentos peregrinos, la comida y su ingesta no sólo constituyen nostalgemas ${ }^{10}$ como signos culturales, sino también actos sociales que ponen en contacto a dos o más personas y que median los significados entre ellos (Yúdice, 1993: 20). En cuentos como "Buen viaje, señor presidente", "María dos Prazeres", "Me alquilo para soñar" y "El verano feliz de la señora Forbes", la comida es un síntoma de los cuerpos que negocian su lugar en el mundo con relación a los demás a partir del exilio, la

\footnotetext{
${ }^{9}$ Frau Frida, nacida en Colombia, emigró a Austria y residió en varias ciudades. Neruda se encuentra con el narrador y con Frau Frida en Barcelona, en una escala en barco a Valparaíso. La característica común en estos tres personajes es la errancia. Los tres están de tránsito hacia alguna parte. El sentido también emigra en las diferentes lenguas: Frau Frida es colombiana de nacimiento, habla alemán, es ama de llaves del embajador de Portugal y reside en Barcelona y La Habana.

${ }^{10}$ Denomino "nostalgema" a la menor unidad de sentido que provoca nostalgia. La palabra nostalgia proviene del griego "nostos", yo regreso y "algia", dolor. Luego, la persona que tiene nostalgia regresa con dolor al pasado, a las cosas. En "Buen viaje, señor presidente", los camarones cocinados por Lázara constituyen un nostalgema. Cuando el ex presidente aspira el olor de los camarones exclama “ $¡ \mathrm{iAh}$, el olor de nuestro mar!"”
} 
soledad, la nostalgia, la tristeza y el desarraigo. La comida constituye una articulación de la significación en estos textos.

Si para estos personajes la comida se encuentra vinculada a la identidad cultural, no debe reducirse a una nostalgia esencializada, aun cuando sea la intención del autor (Nyman, 2009: 282). En "El vino y la leche" y "El bistec y las papas fritas", de Mitologías, Roland Barthes (1980) expone el esencialismo de la cultura francesa, al proponer la "francesidad" de esos productos a partir de una semiología del gusto. El vino es francés, como la leche, norteamericana: "Pero la leche sigue siendo una sustancia exótica; lo nacional es el vino" (78). Ambos franceses, el vino y el bistec comparten la "sanguineidad" (saignant en francés), pero lo verdaderamente francés son las papas fritas (no en vano en inglés se conocen como "french fries"), y al respecto, cita una anécdota aparecida en la revista Match acerca del General de Castries, que, al regresar de la guerra en Indochina, pidió papas fritas: “' 'el general de Castries pidió papas fritas para su primera comida' [...] El general conocía bien la simbología nacional, sabía que la papa frita es el signo alimentario de la 'francesidad' " (81). Así, cada país busca la esencia de su cultura en una comida en particular.

La comida constituye un factor importante en cuanto a la construcción de la identidad cultural, en las prácticas sociales, pero también hay que tomar en cuenta el "principio de incorporación" que comunica el cuerpo con el mundo exterior a través de la boca (Fischler, 1998: 276-278). Fischler califica la incorporación de las sustancias de los alimentos como "real" e "imaginaria": "We are what we eat" (278). Así mismo, expresa: "Incorporation is also the basis of collective identity and, by the same token, of otherness. Food and cuisine are a quite central component of a sense of collective belonging" (278). De esa manera, la incorporación de alimentos conlleva el sentido de la esencialización de una determinada cultura.

En ese sentido, mi línea de investigación sigue tanto el pensamiento de Claude Fischler como el de George Yúdice. A diferencia de Baudrillard, para quien el cuerpo es una alegoría del microcosmos, Yúdice (1993), en su artículo "Feeding the Trascendent Body", expresa lo siguiente: "The body is not simply the screen on which the rampant exchange of information and images is captured, it is, rather, the battleground in which subjects are constituted, contradictorily desiring and rejecting prescribed representations" (81). En Doce cuentos peregrinos, la comida y su ingesta no sólo constituyen nostalgemas y signos culturales, sino también un acto social que pone en contacto a dos o más personas y que median los significados entre ellos (Yúdice, 20). 
La comida refleja la personalidad así como construye una subjetividad en relación con los espacios sociales. En su artículo "Food, Self and Identity", Claude Fischler plantea el "principio de incorporación" como un concepto clave para entender la naturaleza del proceso de incorporación de los alimentos en su relación con las representaciones (276). La boca es el órgano fundamental de la incorporación de alimentos. Sin embargo, le preceden la nariz, los ojos y los dedos en cuanto a la percepción sensorial de la comida. Si la boca determina lo que se ingiere o no, la piel es el órgano más grande y constituye el límite del cuerpo ${ }^{11}$ La piel es la frontera entre el interior y el exterior. En algunos cuentos, este fenómeno se encuentra metaforizado a través de la comida: Lázara Davis tenía "el color del caramelo en reposo" (35), mientras que la Bella Durmiente "una piel tierna del color del pan" (81). Otras partes del cuerpo adquieren una significación en cuanto a la comida. La Bella Durmiente tenía "los ojos de almendra verde" (81). En el mismo cuento, "El avión de la bella durmiente", el narrador utiliza la sinécdoque que sustituye lo abstracto, "la belleza", por lo concreto, "el olor": "[...] y su piel exhalaba un hálito tenue que sólo podía ser el olor propio de su belleza" (87). Luego, el narrador equipara el olor del pan de la Bella Durmiente con la belleza. Si nos atenemos al "principio de incorporación" es como si quisiéramos "comernos" a la muchacha y con ella incorporar su belleza en nuestro cuerpo. ${ }^{11}$

El olor es un aspecto sensorial importante en cuanto a la manifestación de los alimentos. ${ }^{12}$ En algunos de los cuentos, la comida se manifiesta inmaterialmente a través de los olores. Y aunque los alimentos que emiten esos olores no se incorporen al cuerpo, los olores sí, a través de la nariz. Al igual que los alimentos, los olores pueden ser "malos objetos", y por lo tanto tienen una carga semántica negativa. ${ }^{13}$ En

\footnotetext{
${ }^{11}$ Se considera la piel como órgano porque un órgano es un conjunto de tejidos que cumplen funciones específicas. La piel puede incorporar y excretar sustancias a través de los poros. De hecho, la ingestión de algunos alimentos se manifiesta a través del olor de la sudoración. En "Buen viaje, señor presidente", el narrador expresa: "Lo único que delataba el estado de su salud era el cansancio de la piel" (24). La piel "cansada" no sólo connota su enfermedad, sino también su edad. La piel está cansada a causa de su roce con el mundo exterior durante tantos años.

${ }^{12}$ Las metáforas olfativas se encuentran entre las más difíciles en español. Así mismo, el verbo "oler" lleva necesariamente la preposición "a": oler a + el nombre del objeto. La percepción de la comida se expresa a través de sinestesias. El olfato tiene una relación primero con la vista y luego con el gusto. Frente al estímulo olfativo de una comida surge una imagen de la misma y las papilas secretan saliva. En "Buen viaje, señor presidente", el ex presidente aspira el olor de los camarones e inmediatamente irrumpe en su mente la imagen del mar Caribe.

${ }^{13}$ Los alimentos que provocan el rechazo de la incorporación remiten a los "malos objetos" de Melanie Klein. Aunque García Márquez compara el proceso de la escritura con el de la cocción de una sopa ("Prólogo", 19), en varios cuentos la incorporación de la sopa es negativa. En "El verano feliz de la señora Forbes", los niños detestan la sopa de fideos, que comparan con lombrices, y uno de ellos vomita al probar una "murena". En "María dos Prazeres", la protagonista amenaza al Conde con echarle veneno en la sopa. En "Diecisiete ingleses envenenados", Prudencia Linero prefiere comerse una sopa de fideos antes que comer "pajaritos cantores".
} 
"Diecisiete ingleses envenenados", las aguas del puerto de Nápoles despedían un hedor a podredumbre: "[...] una tufada insoportable que la señora Prudencia Linero reconoció como el aliento a cangrejos podridos del patio de su casa" (162). Luego, en el barco, ella se siente "Aturdida por el júbilo y el tufo a cebollas rancias de tantas familias en verano" (163). ${ }^{14}$ En este cuento, el pan no connota la apetecible piel de la Bella Durmiente, sino que, acompañado con la cebolla, connota pobreza. Los olores de los mariscos podridos y la cebolla anuncian la muerte por envenenamiento de los turistas ingleses. En "Espantos de agosto", el olor a fresas es la manifestación del fantasma de Ludovico, quien asesinó a su amante, poco después de haber hecho el amor con ella, y luego se suicidó, haciéndose despedazar por sus propios perros en el castillo renacentista en Arezzo, Italia. ${ }^{15}$ Las fresas, como símbolo del amor, remiten a la amada asesinada en un arrebato de pasión. ${ }^{16}$

El narrador expresa: “Sin embargo, lo que más me impresionó fue el olor de fresas recientes que permanecía estancado sin explicación posible en el ámbito del dormitorio" (131). Y también: "Sólo entonces me estremeció el olor de fresas recién cortadas [...]" (133). El olor a fresas desencadena el acto mágico que consiste en que el narrador y su esposa se acostaran en un dormitorio y amanecieran en otro: en el de Ludovico y en la misma cama en que la bella amante fue asesinada. Los cuerpos de la pareja se colocan en el espacio del castillo en una relación mágico-gastronómica ${ }^{17}$ con respecto al pasado y el presente, y al allá/aquí de la peregrinación a través del olor de las fresas.

La piel, como límite del cuerpo, y los demás órganos, que permiten la percepción de las cualidades de la comida, sonimportantes con relación

\footnotetext{
${ }^{14}$ Este olor emigra semánticamente a un sacerdote que "comía cebollas con pan en un lugar apartado" (169).

${ }^{15}$ En la mitología griega, el célebre cazador Acteón fue transformado en venado por Artemisa (Diana cazadora) como castigo por haberla visto desnuda. Acteón fue devorado por sus propios perros. Este devoramiento se traduce en un acto erótico. ${ }^{16}$ Las fresas connotan amor a causa de su color rojo y forma de corazón. La palabra "fresa" proviene del latín "fraga", derivada de "fragum", fragante, por el fuerte olor que despide esta fruta. Las fresas son un símbolo de Venus, la diosa romana del sexo, el amor, la belleza y la fertilidad.

${ }^{17}$ Otro ejemplo de lo que denomino "realismo mágico-gastronómico" lo constituye el rastro de sangre que deja Nena Daconte en la nieve en el cuento "El rastro de tu sangre en la nieve". Aunque parezca lejana la relación, las gotas de sangre de Nena Daconte, quien moriría desangrada, a lo largo de muchos kilómetros, tiene su correlato en el filete que Billy Sánchez se come en una cafetería en París: "[M]ientras trataba de poner la cabeza en su puesto, ordenó un filete de ternera con papas fritas y una botella de vino" (237). Aquí se encuentran reunidos los tres alimentos que, según Barthes, connotan la "francesidad". Tanto el filete como el vino participan de la sanguineidad. De alguna manera, hay una conexión mágica entre el desangramiento de Nena Daconte la noche anterior y el filete saignant que Billy Sánchez se come al día siguiente.
} 
al espacio exterior. Pero la boca es el órgano más importante en cuanto a la incorporación de los alimentos del exterior en la anatomía del cuerpo. En las secciones subsiguientes voy a concentrarme en cuatro cuentos en los que la gastronomía juega un papel preponderante: "Me alquilo para soñar", "El verano feliz de la señora Forbes", "Buen viaje, señor presidente" y "María dos Prazeres". Así mismo, desglosaré en las notas aquellos aspectos de la gastronomía que, aunque marginales, tienen una fuerte carga semántica.

\section{Pablo Neruda: "el goloso de la vida"}

En "Me alquilo para soñar" se narra la historia de Frau Frida, una misteriosa mujer que había sido ama de llaves del embajador de Portugal en La Habana y que tenía la capacidad de predecir el futuro en sueños que debía contar en ayunas. ${ }^{18}$ En una visita a Barcelona, el narrador cuenta el encuentro con Frau Frida y con el poeta chileno Pablo Neruda, a quien invitaron a cenar:

No he conocido a nadie más parecido a la idea que uno tiene de un Papa renacentista: glotón y refinado [...] Matilde, su esposa, le ponía un babero que parecía más de peluquería que de comedor [...] Aquel día en Carvalleiras fue ejemplar. Se comió tres langostas enteras descuartizándolas con una maestría de cirujano, y al mismo tiempo devoraba con la vista los platos de todos, e iba picando un poco de cada uno, con un deleite que contagiaba las ganas de comer: las almejas de Galicia, los percebes del Cantábrico, las cigalas de Alicante, las espardenyas de la Costa Brava. Mientras tanto, como los franceses, sólo hablaba de otras exquisiteces de cocina, y en especial de los mariscos prehistóricos de Chile que llevaba en el corazón. De pronto dejó de comer, afinó sus antenas de bogavante [...]" (98-99).

En este extenso fragmento, se caracteriza/caricaturiza al poeta Pablo Neruda. Es un esbozo lleno de gracia entre dos amigos: García Márquez y Pablo Neruda. El humor se revela en frases como la siguiente: "Papa renacentista: glotón y refinado", que posee una aparente contradicción, ya que se supone que un glotón debe ser grosero y no tener modales. La lista de los mariscos de las costas

\footnotetext{
${ }^{18}$ Es interesante notar que Frau Frida revela los sueños en ayunas, que es la ausencia de ingestión de comidas. Todo lo contrario a Neruda, que es connotado como un glotón.
} 
españolas sirve de referencia a los mariscos "prehistóricos de Chile" que lleva en su corazón, lo cual refuerza la identidad entre el poeta y su cultura.

En su errancia por diferentes países, una de las formas en que el cuerpo de Neruda se posiciona frente al mundo es como exceso barroco, como "goloso de la vida" y prolífico poeta: "El mundo/es una mesa/rodeada por la miel y por el humo,/ cubierta de manzanas o de sangre./ La mesa preparada/ y ya sabemos cuando/ nos llamaron" (Neruda citado por Daydí-Tolson, 2012: 137). Además de engullir los mariscos y toda la comida que puede ver, devora con sus ojos el mundo para transformarlo en poesía. Así mismo, el poeta "contagia" (como una enfermedad) las ganas de comer. Su gula por la comida, por la vida, se propaga entre los lectores. Como gourmand, Neruda escribió odas elementales dedicadas a la comida: al tomate, a la cebolla, a la papa, a las papas fritas, a la sal, a la alcachofa y al caldillo de congrio, entre otras. ${ }^{19}$ En el cuento, Neruda escribe con la misma pasión con la que come: "[...] [S]e sentó en una mesa apartada, y empezó a escribir versos fluidos con la pluma de tinta verde con que dibujaba flores y peces y pájaros en las dedicatorias de sus libros" (101). Si la relación de Neruda con el mundo, a través de la comida, es de "incorporación" de la realidad, la de la señora Forbes, en otro cuento, consiste en el manejo de platillos como castigo/ recompensa de los cuerpos que quiere controlar, incluso el suyo.

\section{La señora Forbes o el dulce deseo de la pasión}

En "El verano feliz de la señora Forbes", una institutriz alemana se queda al cuidado de dos niños durante un verano en que los padres se encuentran de viaje. Tanto la señora Forbes, de Dortmund, Alemania, como los niños y sus padres, de Guacamayal, Colombia, se encuentran desplazados, en tránsito, veraneando en la isla Pantelleria, en el Mediterráneo. Cabe destacar que ni Dortmund ni Guacamayal son grandes centros urbanos, así como tampoco la isla. La señora Forbes les habla a los niños en un inglés "pedregoso" y en algunas ocasiones habla en alemán "melodioso" y en italiano.

La comunicación entre la institutriz y los niños se establece a través de la comida. La señora Forbes impone estrictas normas de conducta, acordes con el estereotipo de la disciplina de la cultura alemana. A través de un sistema de puntuación, los niños tienen derecho a una

\footnotetext{
${ }^{19}$ Véase el excelente ensayo “Imagen y palabra: el arte del bodegón y la poesía nerudiana”, donde Santiago Daydí-Tolson (2012) analiza la comida en la obra nerudiana.
} 
doble ración de postre al alcanzar los cincuenta puntos: "[N]unca volvimos a encontrar unos budines más deliciosos que los de la señora Forbes" (191); "sus pasteles de crema, sus tartas de vainilla, sus exquisitos bizcochos de ciruelas, como no habíamos de conocer otros en el resto de nuestras vidas" (194). Entre las reglas de etiqueta, había que sentarse a la mesa "[...] con la espina dorsal apoyada en la silla, masticando diez veces con un carrillo y diez veces con el otro" (192). Los niños entablan una relación de odio/amor con respecto a la comida. Si por un lado adoran los budines, por el otro detestan la sopa: "la eterna sopa de fideos de aquel verano aborrecible" (192). "-Estoy hasta los cojones de esta agua de lombrices" (201), expresó uno de los niños. Otro comentó que no le gustaba la "murena" que sirvieron para la cena, a lo que la señora Forbes respondió con una elaborada explicación histórica y cultural acerca de aquel pescado. Al probar el primer bocado, el niño vomitó, por lo que fue castigado con no comer postre. Al final, los niños intentan envenenar a la señora Forbes, pero esta muere asesinada de veintisiete puñaladas.

La señora Forbes establece con los dos niños una relación abyecta a través de la comida. Acaso una relación fantasmagórica que expresa la abyección de la madre ausente. La morena (serpiente acuática) como símbolo fálico está presente en la "solteronería" de la señora Forbes, que a la vez asume una masculinidad en la ropa ("botas de miliciano", "el pelo cortado como el de un hombre bajo el sombrero de fieltro", "voz de soldado") (196-197), así como en su autoritarismo y disciplina ("sargenta de Dortmund") (196). La morena, que aterroriza a los niños, tiene a su vez "ojos de gente". Si por un lado, quiere obligar a los niños a "comerse" la morena, por otro, se regala con torta y vino en la privacidad de su recámara. La señora Forbes se gratificaba a sí misma con la comida con que castigaba a los niños: "[M]ientras comía tratas enteras y se bebía hasta una botella de vino especial que mi padre guardaba con tanto celo para las ocasiones memorables" (199); y también: "[L]a vimos [...] llevando para el dormitorio medio pastel de chocolate y la botella con más de cuatro dedos del vino envenenado" (202).

A diferencia de la Bella Durmiente, cuya piel "exhalaba un hálito tenue que sólo podía ser el olor propio de su belleza" (87), la señora Forbes "Olía a orines de mico" (197). El padre les dice a los niños: "Así huelen todos los europeos, sobre todo en verano [...] Es el olor de la civilización" (197). La piel "color del pan" (54) de la Bella Durmiente, que exhala un olor a belleza, invita a ser "incorporada" a nuestro cuerpo, a través de los sentidos, y más específicamente, a través de la boca. Comerse a la Bella Durmiente, que es latinoamericana, es asimilar su belleza en un proceso de transustanciación. Por el 
contrario, la piel de la señora Forbes impone un límite preciso de noincorporación a causa del olor a orines de mono. Metonímicamente, el asco que produce la señora Forbes constituye un rechazo a la cultura europea.

El cuerpo "escuálido"20 de la señora Forbes expresa su relación con el mundo: la gula y el alcoholismo de un cuerpo que, sin embargo, no engorda, un cuerpo que no está hecho para ser amado. La forma en que la señora Forbes construye el sentido y su relación con los demás en el mundo es a través de los postres y el vino, que vienen a sustituir el erotismo ausente en su cuerpo. En la privacidad de su recámara, la señora Forbes ve películas pornográficas, mientras come tartas y bebe vino. Pero la piel de la señora Forbes es perforada por los cuchillos, lo que implica que su cuerpo es comunicado violentamente con el exterior. Aunque el acto del crimen se encuentra omitido en el cuento, es posible que haya sido Oreste el autor de ese crimen pasional. Al principio del cuento, cuando la señora Forbes ve a Oreste queda prendada de su belleza: "[...] era imposible concebir un ser humano más hermoso" (190). La señora Forbes fue víctima de su propia pasión por la belleza.

\section{"Buen viaje, señor presidente" o la piel cansada}

En el cuento "Buen viaje, señor presidente", un ex presidente caribeño exiliado en Martinica se encuentra de visita en Ginebra para consultas médicas e intervención quirúrgica. El cuerpo del ex presidente (sin nombre) es un cuerpo enfermo. Su dolor es tanto físico como emocional (nostalgia). Los órganos son detallados en la narración: "Buscaban el dolor en el hígado, en el riñón, en el páncreas, en la próstata, donde menos estaba [...] Su dolor era improbable y escurridizo, y a veces parecía estar en el costillar derecho y a veces en el bajo vientre, y a menudo lo sorprendía con una punzada instantánea en la ingle" (24). El cuerpo de órganos enfermos del ex presidente tiene su antítesis en la Santa, en el cuento del mismo nombre, cuyo cuerpo es ingrávido, un cuerpo sin órganos: "Lo más asombroso, sin embargo, era que el cuerpo carecía de peso" (61). El cuerpo de órganos enfermos es un cuerpo para la muerte; el de la santa, es incorruptible.

El ex presidente se encuentra con un coterráneo que lo reconoce. Lo invita a comer al restaurante Le Boeuf Couronné. En el mismo,

\footnotetext{
${ }^{20}$ La palabra "escuálido" está relacionada etimológicamente con escualos, tiburones. El cuerpo de la señora Forbes tiene forma de pez o tiburón.
} 
el ex presidente ordena, además de la ensalada con aceite de oliva, la especialidad de la casa: costillas de buey al carbón: “[...] y vieron en las otras mesas los grandes trozos asados con un borde de grasa tierna" (30). Para el ex presidente, que se encuentra en la pobreza, esta significa la oportunidad no sólo de calmar su hambre, sino también de degustar un platillo especial. Luego, el paisano suyo lo invita a su casa para degustar un arroz con camarones, la especialidad de su mujer. Lo único es que los camarones que ella prepara son enlatados. Al entrar a la casa, el ex presidente "exclamó con los ojos cerrados y los brazos abiertos: “ $\mathrm{iAh}$, el olor de nuestro mar!'” (39). Luego, el ex presidente "se sirvió dos veces sin medirse en los elogios, y le encantaron las tajadas fritas de plátano maduro y la ensalada de aguacate, aunque no compartió las nostalgias" (40. La cursiva es mía). Tanto las costillas asadas como los camarones, los plátanos maduros y el aguacate constituyen una falacia nostálgica, ya que son productos que se pueden producir/adquirir en otras partes del mundo, que no son única y exclusivamente del Caribe. Su cuerpo, despojado de los placeres de la mesa por las prohibiciones de su médico, trata de situarse metonímicamente con relación a la nación de la cual está ausente.

La prohibición consiste en la incorporación de "objetos buenos" como el café y el alcohol, que la nostalgia reclama. El café no es sólo una bebida de la cultura, sino también un elemento cognitivo. En varias ocasiones, el ex presidente se lee la taza para conocer su destino: "Se lo tomó sin azúcar, a sorbos lentos, y después puso la taza bocabajo en el plato para que el sedimento del café, después de tantos años, tuviera tiempo de escribir su destino [...] Antes de quitarse los lentes descifró su destino en el asiento del café, y sintió un estremecimiento glacial: allí estaba la incertidumbre" (27). La bebida, en este caso, es cifra y escritura del cuerpo. A sus setenta y cinco años, el ex presidente deja de leerse la taza, rompe con la prohibición médica y decide comer de todo y volver a fumar, decide "vivir la vida como viniera" (55).

\section{María dos Prazeres o los placeres del sexo}

Si en el cuento "Espantos de agosto" el olor a fresas connota mágicamente el asesinato de la amante de Ludovico, en "Maria dos Prazeres" el olor a arenque ahumado connota, por una parte, la atmósfera vetusta del apartamento, y por otra, en el código de la cultura popular, el sexo de la protagonista, vieja prostituta retirada. ${ }^{21}$

\footnotetext{
${ }^{21}$ El olor del pescado, o específicamente del arengue, como connotación del olor del sexo femenino constituye una doxa en la cultura popular latinoamericana.
} 
El evento gastronómico más significativo en el cuento "María dos Prazeres", al cual me he referido anteriormente, es la cena que la protagonista prepara. El conde de Cardona la visitaba "el último viernes de cada mes para cenar con ella y hacer un lánguido amor de sobremesa" (144). La cena consistía en champaña local (cava), trufas rellenas, canelones gratinados, pollo tierno en su jugo, frutas y oporto. El narrador apunta el estatus de clase social de esa cena: "que eran los platos favoritos de los catalanes de alcurnia de los buenos tiempos" (149). La relación entre María dos Prazeres es contractual y se debe a un viejo hábito entre los dos. El conde le deja veinticinco pesetas como pago por sus servicios. De ahí que el narrador vuelva a enfatizar el tipo de relación entre estos dos personajes: "Después de la cena, larga y bien conversada, hacían de memoria un amor sedentario que les dejaba a ambos un sedimento de desastre" (149). La sobremesa, que consiste en el tiempo después de la comida que se utiliza para charlar, es usada por estos personajes para tener sexo.

A sus setenta y un años el cuerpo de María es un cuerpo que se prepara para la muerte. María, "abandonada sin dinero, sin idioma y sin nombre [...]" (150); "[...] Se sintió fea y compadecida" (154). Un cuerpo que en el pasado estuvo hecho para los placeres (no en vano su apellido) del sexo y la comida, es ahora un cuerpo para la muerte que había previsto en un sueño. Es por ello que compra de antemano su tumba en el cementerio de Mont Juic y le enseña a su único compañero, el perro, a tomar el autobús para que visite su tumba cuando muera. ¿Es el cementerio un no-lugar? Es un lugar en el que podemos relacionarnos afectivamente con los familiares y amigos fallecidos y enterrados allí. Lo único extraño, en este caso, es que el perro será el único que vaya por voluntad propia a visitarla.

\section{Conclusión}

En Doce cuentos peregrinos, de Gabriel García Márquez,la comida tiene la función, por una parte, de establecer el carácter, el estatus social y la identidad cultural de los personajes, y por otra, de instaurar una poética relacional en el espacio social en que se desenvuelven dichos personajes. Las referencias culinarias en estos cuentos, además de estar ligadas a la cultura de los países a los cuales pertenecen esos personajes, constituyen un desplazamiento o una paratopía de los cuerpos con respecto a su lugar de origen. Gabriel García Márquez convierte la peregrinación, a partir de su errancia durante dieciocho años, en una poética que gobierna los cuentos de esta colección. Dicha poética se expresa en la extrañeza y "desfamiliarización" de los personajes desplazados por ciudades europeas. La gastronomía 
juega un papel preponderante en la construcción de la subjetividad de los personajes. Aunque las referencias a la gastronomía abundan en otros textos del autor colombiano, Doce cuentos peregrinos constituye un libro único en cuanto a la articulación de la comida con cuerpos que buscan expresarse.

\section{Bibliografía}

Amiran, Eyal, \& John Unsworth. (Eds). (1993). Essays in Postmodern Culture. Oxford: Oxford. University Press.

Augé, Marc. (1995). Non-places: Introduction to an anthropology of supermodernity. [Trans. John Howe]. London \& New York: Verso.

Barthes, Roland. (1980). Mitologías. Madrid: Siglo XXI Editores.

Clancier, Anne. (1979). Psicoanálisis, Literatura, Crítica. Madrid: Cátedra.

Daydí-Tolson, Santiago. (2012). "Imagen y palabra: el arte del bodegón y la poesía nerudiana”, Cincinnati Romance Review, no 33, pp. 133-144

Fischler, Claude. (1998). "Food, Self and Identity." Social Sciences Information, no 27, pp. 275-293.

García Márquez, Gabriel. (1992). Doce cuentos peregrinos. Madrid: Mondadori. Lejeune, Philippe. (1996). Le pacte autobiographique. París: Éditions du Seuil. Nyman, Jopi. (2009). "Cultural Contact and the Contemporary Culinary Memoir: Home, Memory and Identity in Madhur Jaffrey and Diana Abu-Jaber", Autobiographical Stydies, vol. XXIV, no 2 pp. 282-298.

Pugh Briceño, Karina (2000). "Los Strange Pilgrimsy gastronómicos de Gabriel García Márquez": http://www.afuegolento.com/ noticias/44/firmas/karina/1826/los-doce-cuentos-peregrinosy-gastronomicos-de-gabriel-garcia-marquez. [Consultado el 29 de junio de 2015].

Valerio Holguín, Fernando. (2016). "Gabriel García Marquez: Pilgrimage and Gastronomy". En Bell-Villada, Gene H. (Ed.). (2016). Gabriel García Marquez in Retrospect. Lanham: Lexington Books, pp. 147-164.

Vanden Berghe, Kristine. (2001). "Los Doce cuentos peregrinos de García Márquez. ¿O son trece? Paratopía, parodia e intertextualidad en Doce cuentos peregrinos", Bulletin of Hispanic Studies, vol. LXXXVI, pp. 85-98.

Yúdice. George. (1993). "Feeding the Trascendent Body". En Eyal Amiran \& John Unsworth. (Eds.). (1979). Essays in Post Modern Culture. Oxford: Oxford University Press, pp. 13-36. 